IRA-International Journal of Applied Sciences ISSN 2455-4499; Vol.04, Issue 01 (2016)

Institute of Research Advances

http://research-advances.org/index.php/IRAJAS

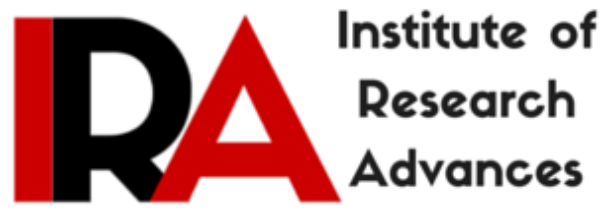

\title{
Synthesis and Characterization of Molybdenum Doped ZnO Thin Films by SILAR Deposition Method
}

\author{
${ }^{1}$ R. Radha, ${ }^{2}$ A. Sakthivelu \& ${ }^{3}$ D. Pradhabhan \\ ${ }^{1,2,3}$ PG \& Research Department of Physics, \\ Periyar.E.V.R College, Trichy, India.
}

DOI: http://dx.doi.org/10.21013/jas.v4.n1.p10

\section{How to cite this paper:}

Radha, R., Sakthivelu, A., \& Pradhabhan, D. (2016). Synthesis and Characterization of Molybdenum Doped ZnO Thin Films by SILAR Deposition Method. IRA-

International Journal of Applied Sciences (ISSN 2455-4499), 4(1).

doi:http://dx.doi.org/10.21013/jas.v4.n1.p10

(C) Institute of Research Advances

\section{(cc) EY-NC}

This works is licensed under a Creative Commons Attribution-Non Commercial 4.0 International License subject to proper citation to the publication source of the work.

Disclaimer: The scholarly papers as reviewed and published by the Institute of Research Advances (IRA) are the views and opinions of their respective authors and are not the views or opinions of the IRA. The IRA disclaims of any harm or loss caused due to the published content to any party. 


\begin{abstract}
Molybdenum (Mo) doped zinc oxide $(\mathrm{ZnO})$ thin films were deposited on the glass substrate by Successive Ionic Layer Adsorption and Reaction (SILAR) deposition method. The effect of Mo dopant concentration of 5, 6.6 and $10 \mathrm{~mol} \%$ on the structural, morphological, optical and electrical properties of n-type Mo doped $\mathrm{ZnO}$ films was studied. The X-ray diffraction (XRD) results confirmed that the Mo doped $\mathrm{ZnO}$ thin films were polycrystalline with wurtzite structure. The field emission scanning electron microscopy (FESEM) studies shows that the surface morphology of the films changes with Mo doping. A blue shift of the optical band gap was observed in the optical studies. Effect of Mo dopant concentration on electrical conductivity was studied and it shows comparatively high electrical conductivity at $10 \mathrm{~mol} \%$ of Mo doping concentration.
\end{abstract}

Keywords: SILAR, ZnO thin films, Mo- doping, surface morphology, electrical properties

\title{
1. Introduction
}

Zinc oxide $(\mathrm{ZnO})$ has attracted a considerable number of researchers over the last two decades because it is a promising material for electronic and optoelectronic device application such as solar cells, photo-catalysis, surface acoustic devices, piezoelectric transducers, gas sensors, liquid crystal displays, heat mirrors, etc.[1,2] and also $\mathrm{ZnO}$ has been actively investigated as an alternate material to ITO. Because it is an inexpensive, nontoxic and abundant compared to ITO [3, 4]. The electrical conductivity of zinc oxide depends on the carrier concentration contributed by oxygen vacancies or interstitial metal atoms in it [5]. Therefore, forming an $n$ type semiconductor structure by doping boron, aluminium, gallium and indium is a recognized method for improving the conductivity of zinc oxide. Molybdenum doped zinc oxide is the most potential one over these materials. The ionic radii of $\mathrm{Mo}^{6+}$ is $(0.41 \AA)$ and that of $\mathrm{Zn}^{2+}$ is $(0.60 \AA)$, thus it is theoretically possible for $\mathrm{Mo}^{6+}$ to substitute $\mathrm{Zn}^{2+}$ in the $\mathrm{ZnO}$ lattice[6,7]. Moreover, $\mathrm{Mo}\left([\mathrm{Kr}]: 4 \mathrm{~d}^{5} 5 \mathrm{~s}^{1}\right)$ is the more beneficial impurity to be doped into the $\mathrm{ZnO}$ matrix as it can donate 4 electrons to the free carriers due to the high valence difference between $\mathrm{Mo}^{6+}$ ions and substituted $\mathrm{Zn}^{2+}$ ions. Therefore, very small amount of Mo doping can give enough free carriers and reduce the ion scattering effect [8]. Moreover, Mo exhibits multiple valence states of $+6,5,4,3,2$ and this enables the contribution of multiple carriers by a single Mo dopant atom [9]. Undoped and $\mathrm{Mo}$ doped $\mathrm{ZnO}$ (MZO) thin films have been grown by various deposition techniques such as RF/DC sputtering [10,11], ion beam sputtering deposition (IBSD) [12], spray pyrolysis [13] and Successive Ionic Layer Adsorption and Reaction(SILAR) deposition method[14,15]. Among these methods SILAR method only having more advantages like, large-scale deposition in glass and metal substrates, commercial-grade production in non-vacuum conditions at low temperatures and low cost [16]. In the present work the Mo doped $\mathrm{ZnO}$ films were deposited for various molar ratios of Mo and $\mathrm{Zn}(1: 10,1: 15$ and 1:20) and in the present investigation, the effect of Mo doping on various physical properties like structure, surface morphology, optical properties and electrical properties of $\mathrm{ZnO}$ thin films was studied in detail.

\section{Experimental procedure}

All the reagents used in the present work for the chemical synthesis were of analytical grade and all the solutions were prepared in Millipore water. For the preparation of Mo doped $\mathrm{ZnO}$ thin films, cationic precursor $(0.1 \mathrm{M})$ zinc acetate $(50 \mathrm{ml})$ and $(0.01 \mathrm{M})$ molybdenum $(\mathrm{v})$ chloride were taken in a beaker and the anionic precursor $(0.1 \mathrm{M})$ Sodium thio sulphate $(50 \mathrm{ml})$ was taken in a separate beaker. For the deposition of Mo doped $\mathrm{ZnS}$ thin film, well cleaned glass substrate was dipped into the cationic precursor for $15 \mathrm{sec}$ for adsorption of $\mathrm{Zn}^{2+}$ and $\mathrm{Mo}^{6+}$ ions on the surface of the glass substrate, and then the substrate was dipped into the de-ionized water for $10 \mathrm{sec}$ to avoid precipitation and also to remove the loosely bounded cations. The substrate was then immersed into the anionic precursor bath for $15 \mathrm{sec}$ for reaction of $\mathrm{S}^{2-}$ ions with $\mathrm{Zn}^{2+}$ and $\mathrm{Mo}^{6+}$ ions on the surface of the glass substrate. The procedure was carried out at around $75^{\circ} \mathrm{C}$ temperature. Successive dipping cycles repeated up to 50 cycles, to get the well adherent and homogeneous Mo doped $\mathrm{ZnO}$ thin films [14]. Then the same procedures were repeated for 0.0066 and 0.005 mol of molybdenum (v) chloride. Mo was doped with $\mathrm{Zn}$ in the following molarity ratio $\mathrm{Zn10:} \mathrm{Mo01,} \mathrm{Zn15:} \mathrm{Mo01} \mathrm{and} \mathrm{Zn20:} \mathrm{Mo01}$ and the corresponding mol percentages are 10,6.6 and 5 respectively. The prepared samples were 
annealed in air at $450^{\circ} \mathrm{C}$ for 3 hours. Phase identification and crystalline properties of the films were studied by XPERT-PRO X-ray powder diffractometer with $\mathrm{CuK} \alpha$ radiation $(\lambda=1.5418 \AA$ ). Scanning electron microscopy FE-SEM $6701 \mathrm{~F}$ used to study the surface morphology and to illustrate the formation of crystallites on the film surface. UV-VIS spectrophotometric measurements were performed using a Unico UV-2102PCS spectrophotometer at room temperature. The electrical parameters were measured using Hall measurements setup (ECOPIA-HMS 3000) at room temperature with the permanent magnet of 0.57 Tesla.

\section{Result and Discussion}

\subsection{Structural Analysis}

The crystal structure of Mo doped $\mathrm{ZnS}$ films were determined by XRD spectra obtained by grazing incidence $\mathrm{X}$-ray diffraction. Fig.(1) shows the X-ray diffraction spectra of the SILAR deposited Mo doped $\mathrm{ZnS}$ films, which exhibits the $\mathrm{X}$-ray diffraction spectra of $\mathrm{ZnO}$, it is believed that, during annealing in air at $450^{\circ} \mathrm{C}$ for 3 hours, presence of sulphur has been decomposed by oxidation process[14\&15]. The Mo doped $\mathrm{ZnO}$ films were observed to be $c$-axis oriented films with strong (002) orientation, which indicates the hexagonal wurtzite structure of $\mathrm{ZnO}$ [17]. In the diffraction pattern, peaks corresponding to the (100), (002) and (101) planes of hexagonal $\mathrm{ZnO}$ are observed. The diffraction pattern exhibits the entire characteristic peaks of the Zincite $\mathrm{ZnO}$ hexagonal structure, which is good agreement with the reported standard values (ICDD No. 36-1451). In the diffraction pattern, (002) reflection was the prominent peak than the other peaks, which indicates that all the deposited films are (002) preferred oriented along the c-axis and perpendicular to the surface of the substrate. Intensity of the (002), (100) and (101) diffraction peaks were decreased with increasing the Mo concentration, which indicates that excessive Mo doping deteriorates the crystallinity of the films, which may be due to the formation of stress by the smaller radius of $\mathrm{Mo}^{6+}$ ions $(0.41 \AA)$ compared with $\mathrm{Zn}^{2+}$ ions $(0.60 \AA)$ [6,7]. In order to determine lattice parameter of the thin films, JANA2006 code was used in the Le-Bail mode. The calculated lattice parameter and unit cell volume of thin films were tabulated in Table.1. The calculated values of lattice parameters a and $\mathrm{c}$ for $5 \mathrm{~mol} \%$ of Mo doped zinc oxide are 3.245 and $5.204 \AA$ respectively and these values are found in good agreement with the corresponding values of $3.249 \AA$ and $5.206 \AA$ [ICDD No. 36-1451]. It can also found that, with the increase of the doping concentration of Mo from $5 \mathrm{~mol} \%$ to $10 \mathrm{~mol} \%$, lattice constant (a) decreased linearly from 3.245 to $3.241 \AA$ and c decreased from 5.204 to $5.199 \AA$. The slight change of lattice parameter of Mo doped $\mathrm{ZnO}$ also prove that the Mo ions were incorporated into the $\mathrm{ZnO}$ lattice. Moreover it was known that the difference in lattice parameter $\mathrm{c}$ could be related to the result of stress relaxation in the films [18]. The $2 \theta$ of the (002) was shifted to higher values of $2 \theta$ (from 34.40 to $34.49^{\circ}$ ), when Mo was incorporated and indicates reduction of inter-planar spacing " $d$ " in the films. Also the crystallographic (002) peak becomes broad with increasing molybdenum concentration. The literature reveals that the reduction in the intensity of the crystallographic peak is attributed to the reduction in the crystallinity of the films $[19,20]$. The crystallite size of the SILAR deposited Mo doped $\mathrm{ZnO}$ thin films has been calculated using Scherer formula [21] given in equation (1), and the average lattice strain has been calculated using Stokes Wilson equation [22] shown in equation (2), The FWHM values of the samples were derived from their highest intensity peak broadening by pseudo-voigt peak fitting.

Crystallite size $\mathrm{D}_{\mathrm{ave}}=0 \cdot 94 \lambda / \beta \cos \theta$

Micro Strain $\varepsilon=\beta / 4 \tan \theta----$ (2)

Where $D_{\text {ave }}$ is the mean crystallite size, $\varepsilon$ is the average micro strain $(\Delta d / d), \beta$ the full width at half maximum of the diffraction line, $\theta$ angle of diffraction, and $\lambda$ the wavelength of the $\mathrm{X}$-ray radiation.

The maximum crystallite size of $\sim 37 \mathrm{~nm}$ is found for $5 \mathrm{~mol} \%$ Mo doped film and the minimum crystallite size of $\sim 30 \mathrm{~nm}$ is found for $10 \mathrm{~mol} \%$ of Mo doped film which is shown in Table.01. Reduction of c/a ratio and unit cell volume of $\mathrm{ZnO}$ thin films supports the Mo doping into the $\mathrm{ZnO}$ lattice. The texture coefficient is calculated to describe the preferential orientation of the prepared Mo doped $\mathrm{ZnO}$ films using the following expression [23] given in equation (3). 


$$
T C(h k l)=\frac{\left[I(h k l) / I_{0}(h k l)\right]}{1 / N \sum_{N}\left[I(h k l) / I_{0}(h k l)\right]}
$$

Where $I(h k l)$ is the measured relative intensity of a plane $(h k l), I_{0}(h k l)$ is the standard intensity of the plane $(h k l)$ taken from [ICDD No. 36-1451], $N$ the number of diffraction peaks. The value TC(hkl)=1 corresponds thin films with randomly oriented crystallites, whereas higher values indicate the abundance of grains oriented in a given [hkl] direction. From the graph (fig.2.b), it is seen that all the films have a preferential orientation along the [002] direction and the higher TC value for (002) plane was observed for Mo doping concentration of $5 \mathrm{~mol} \%$.

\subsection{Surface Morphology and EDAX by FESEM Analysis}

The FESEM micrographs of Mo doped $\mathrm{ZnO}$ thin films with the various mol\% of Mo (5 mol \%, $6.6 \mathrm{~mol} \%$ and $10 \mathrm{~mol} \%$ ) on glass substrates are shown in Fig.3. It can be seen that the surface morphology of the films strongly depends on the concentration of the dopant. Fig. 3(a) and 3(b) shows different magnification $(30,000 \& 50,000 \mathrm{x})$ of $5 \mathrm{~mol} \%$ Mo doped thin films. The grains more or less cover the substrate surface uniformly. However, Mo doped $\mathrm{ZnO}$ film shows particles with rod like and cube like shape. Particles on the surface of substrate were seemed to be agglomerated. Fig. 3(c) \& 3(d) show $6.6 \mathrm{~mol} \% \mathrm{Al}$ doped $\mathrm{ZnO}$ thin films in different magnifications; there seems to be an increase in the surface coverage of grains 3(c). The surface of the $10 \mathrm{~mol} \%$ of Mo doped $\mathrm{ZnO}$ film shows nearly completes coverage (Fig. 3(e)) and reduction in grain size. At higher magnification (3f), the grain formation is observed as irregular agglomeration with different grain sizes and also noticed the orientation decorated with small gains Thus, MO doping seems to have modified the shape of the grains. Also noticed that most of the grains are elongated in one direction, and forms flower like surface morphology. . In comparison with XRD analysis, the reduction of texture coefficient and crystallite size is in good agreement. These observations suggest an incomplete nucleation step with irregular growth rate of the grains. The result shows accelerated grain growth with the Mo doping. The grain size reduces and randomizing of grain orientation occurs easily when Mo dopants were incorporated with $\mathrm{ZnO}$. The surface seems to be formed by the stacking of selfaligned nanoparticles with distinguished micro flower shape.

Although no compositional analysis was attempted in the present study, the incorporation of MO in the films was verified by the EDAX result. Figure 4(a), (b) \&(c) shows the energydispersive X-ray spectrum of $\mathrm{MO}$ doped $\mathrm{ZnO}$ film for $5 \mathrm{~mol} \%, 6.6 \mathrm{~mol} \%$ and $10 \mathrm{~mol} \%$ respectively. The spectrum reveals the presence of $\mathrm{Zn}, \mathrm{O}$ and incorporation of $\mathrm{MO}$ in the deposited films.

\subsection{Optical studies}

The transmittance spectra in the wavelength range of 300-1100 $\mathrm{nm}$ for Mo doped $\mathrm{ZnO}$ thin films are shown in Fig. 5(a). It shows that the transmittance of 6.6 and $10 \mathrm{~mol} \%$ doped films is lower than that of $5 \mathrm{~mol} \%$ films. The decrease in transmittance at higher doping concentrations may be due to the increased scattering of photons caused by rough surface morphology as well as its crystal defects. This result is in good agreement with structural and surface morphology analysis of the present work. Similar behaviour has also been observed by Lee et al. for Sn-doped $\mathrm{ZnO}$ films prepared by the sol-gel method [24]. The optical band gap Eg can be estimated by plotting ( $\square \mathrm{h} \square\}$ versus photon energy ( $\mathrm{h} \square$ ) based on the relation $\square \mathrm{h} \square=\mathrm{A}(\mathrm{h} \square \mathrm{Eg})^{\mathrm{n} / 2}$ where $\square$ is the absorption coefficient, $\mathrm{A}$ is a constant and $\mathrm{n}$ is the exponent depending on quantum selection rule for a particular material[25]. The calculated band gap with respect to Mo doping concentration is plotted in fig. 5(b), clearly indicates increase of band gap with increase in Mo concentration. The optical band gap for 5 mol \% Mo doped $\mathrm{ZnO}$ film is $3.30 \mathrm{eV}$. For $6.6 \mathrm{~mol} \%$ Mo doped $\mathrm{ZnO}$ film the band gap is $3.35 \mathrm{eV}$, which is lower than $10 \mathrm{~mol} \%$ Mo doped $\mathrm{ZnO}$ film $(3.44 \mathrm{eV})$. The optical band gaps presented in Fig. 5(b) clearly exhibit a shift in band edge towards lower wavelength with the increase in the Mo doping concentration, indicating the broadening of the optical band gap. The change in the optical band gap can be explained in terms of Burstein-Moss shift [26] and also there are several mechanisms that can cause the observed shift of energy gap, such as: degradation or improvement of crystallite, 
modifications in the height of the barrier due to change of the crystalline dimension, quantum size effects, variation in the density of impurity and compressive or tensile strains [27, 28].

\subsection{Electrical Studies}

The Hall measurements of Mo doped $\mathrm{ZnO}$ thin films were performed at room temperature in van der Pauw configuration. The different Hall parameters, such as conductivity, resistivity and carrier concentrations $(n)$ have been calculated and tabulated in Table 2. The variation of the carrier concentration with Mo content is shown in Fig.6 (a). It is shown that Mo content is a parameter which affects the electrical properties of the $\mathrm{ZnO}$ film. It can be observed from Fig. 6(b) that the film shows comparatively the lowest resistivity and the highest conductivity at a Mo doping concentration of 10 mol \%.The increase in the electrical conductivity is due to the presence of large number of free carriers introduced by Mo dopant [29, 30]. This can be explained as follows: when Mo is incorporated in to the $\mathrm{ZnO}$ lattice, $\mathrm{Mo}^{6+}$ replaces $\mathrm{Zn}^{2+}$ ion in the $\mathrm{ZnO}$ crystal structure resulting in four more free electrons that contribute to the electric conduction. So, the increase in the electrical conductivity is due to the presence of large numbers of free carriers introduced by Mo dopant. The highest carrier concentration obtained in the present investigation is $2.109 \times 10^{17} \mathrm{~cm}^{-3}$ and it is observed at $10 \mathrm{~mol} \%$ of Mo doped $\mathrm{ZnO}$ films.

\section{Conclusions}

Polycrystalline Mo doped $\mathrm{ZnO}$ thin films are deposited on glass substrates by SILAR deposition method. The effect of Mo doping on structural, morphological, optical and electrical properties of $\mathrm{ZnO}$ films were studied. The XRD analysis shows that MZO films possess wurtzite structure. When the doping concentration is $5 \mathrm{~mol} \%$, the intensity of (002) peak is much stronger than that of other peaks which indicates that the thin film has a preferential orientation along (002) plane. The FESEM images showed that, up on increasing the Mo content, the surface morphology of the films is uniform and grains are distributed uniformly throughout the surface. Optical studies reveals that, the optical band gap of Mo doped $\mathrm{ZnO}$ thin films increase with increasing Mo content in the samples. Hence, the observed increase in the optical band gap from 3.30 to $3.44 \mathrm{eV}$. From the electrical studies, it is found that the variation in electrical resistivity can be directly attributed to the effect of Mo ion incorporation into the $\mathrm{ZnO}$ lattice. At $10 \mathrm{~mol} \%$ of Mo doping, the films showed highest electrical conductivity. The structural, optical and electrical characterization studies clearly indicate the incorporation of Mo into $\mathrm{ZnO}$.

\section{References}

[1] K Arshak and I Gaiden, Mater. Sci. Engg. B 118 ( 2005) 44.

[2] R Ghosh, S Fujihara and D Basak, J. Electron. Mater. 35 (2006) 1728.

[3] S.J. Henley, M.N.R. Ashfold, D. Cherns, Surf. Coat. Technol 271 (2004) 177.

[4] B.M. Ataev, A.M. Bagamadova, V.V. Mamedov, A.K. Omaev, M.R. Rabadanov, J. Cryst. Growth 198/199 (1999) 1222.

[5] D. Ginley, C. Bright, MRS Bull. 25 (2000) 15.

[6] G. Lu, Z. Z. Ye, Y. J. Zeng et al., "Structural, optical, and electrical properties of (Zn,Al)O films over a wide range of compositions," Journal of Applied Physics, vol. 100, no. 7, Article ID 073714, 11 pages, 2006.

[7] K. Srinivasarao, G. Srinivasarao and K. V. Madhuri, Indian Journal of Materials Science Volume 2013, Article ID 684730.

[8] H.K. Kim, S.H. Huh, J.W. Park, J.W. Jeong, G.H. Lee, Chem. Phys. Lett. 354 (2002) 165.

[9] J. N. Duenow, T. A. Gesset, D. M. Wood, T. M. Barnes, and M.Young, "Transparent conducting zinc oxide thin films doped with aluminum and molybdenum," Journal of Vacuum Science \& Technology, vol. 25, no. 4, p. 955, 2007

[10] X.W. Xiu, Z.Y. Pang, M.S. Lv, Y. Dai, L.N. Ye, S.H. Han, Appl. Surf. Sci. 253 (2007) 3345. 
[11] Y.C. Lin, B.L. Wang, W.T. Yen, C.H. Shen, Thin Solid Films 519 (2011) 5571.

[12]C.C.Kuo,C.C.Liu,S.C.He,J.T.Chang,J.L.He,Vacuum85(2011)961.

[13] J.D.Merchant, M.Cocivera, Chem.Mater 7 (1995) 1742.

[14] R.Radha, A.Sakthivelu, D.Pradhabhan, C.Ravichandiran, S.Murugesan, E.Mohandas and Geethadhevi, International Journal of ChemTech Research, Vol.6, No.6, pp 33743377(2014)

[15]R. Radha, A. Sakthivelu, D.Pradhabhan, C. Ravichandiran, S. Murugesan, \& E. Mohandas, Journal of Scientific Research in Physical \& Mathematical Science Volume (2) Issue (9) Year (2015)ISSN : 2349-7149

[16]C. D. Lokande, B. R. Sankapal, H. M. Pathan, M. Muller, M.Giersig, andH. Tribustch, App. Surf. Sci. ,2001, 181, 277.

[17] K. S. Rao, B. Rajini Kanth, K. Pandurangarao, and P. K. Mukhopadhyay, "Physical investigations on pulsed laser deposited nanocrystalline $\mathrm{ZnO}$ thin films," Applied Physics A, vol. 108, no. 1, pp. 247-254, 2012.

[18] D. Yuvaraj and K. Narasimha Rao, Optical and electrical properties of ZnO films deposited by activated reactive evaporation. Vacuum 82, 1274 (2008).

[19] E. L. Papadopoulou, M. Varda, K. Kouroupis-Agalou et al., "Undoped and Al-doped $\mathrm{ZnO}$ films with tuned properties grown by pulsed laser deposition," Thin Solid Films, vol. 516, no. 22, pp. 8141-8145, 2008.

[20] R. Swapna and M. C. Santhosh Kumar, "The role of substrate temperature on the properties of nanocrystalline Mo doped $\mathrm{ZnO}$ thin films by spray pyrolysis," Ceramics International, vol. 38, no. 5, pp. 3875-3883, 2012.

[21] S Tewari and A Bhattacharjee, Pramana - J. Phys. 76, 153 (2011)

[22] P Shrestha, R Ghimire, J J Nakarmi, Young Sung Kim, S Shrestha, C Y Park and J H Boo, Bull. Korean Chem. Soc. 31, 112 (2010)

[23] Barred c., Massalski t.b., Structure of Metals, Pergamon Press, Oxford,1980, p. 204.

[24] J.H. Lee, B.O. Park, Thin Solid Films 426 (2003) 94.

[25] Muhammad Nafees, Wasim Liaqut, Salamat Ali, Muhammad Ahsan Shafique Appl Nanosci (2013) 3:49-55

[26] B.E. Sernelius, K.F. Berggren, Z.C. Jim, I. Hamberg, C.G. Granqvist, Phys. Rev. B. 37 (1994) 10244.

[27] J. K. Lee, H. M. Kim, S. H. Park, J. Kim, and S. H. Sohn, Heat treatment effects on electrical and optical properties of ternary compound In2O3-ZnO films. J. Appl.Phys. 92, 5761 (2002).

[28] M. Suchea, S. Christoulakis,M. Katharakis, N.Vidakis, andE.Koudoumas, Influence of thickness and growth temperature on the optical and electrical properties of $\mathrm{ZnO}$ thin films. Thin Solid Films 517, 4303 (2009).

[29] Y. Zhou, P.J. Kelly, Thin. Solid. Films 18 (2004) 469.

[30] R.F. Pierret, Semiconductor Device Fundamentals, Addison-Wesley Publish,USA, 1996. 
(Tables \& Figures)

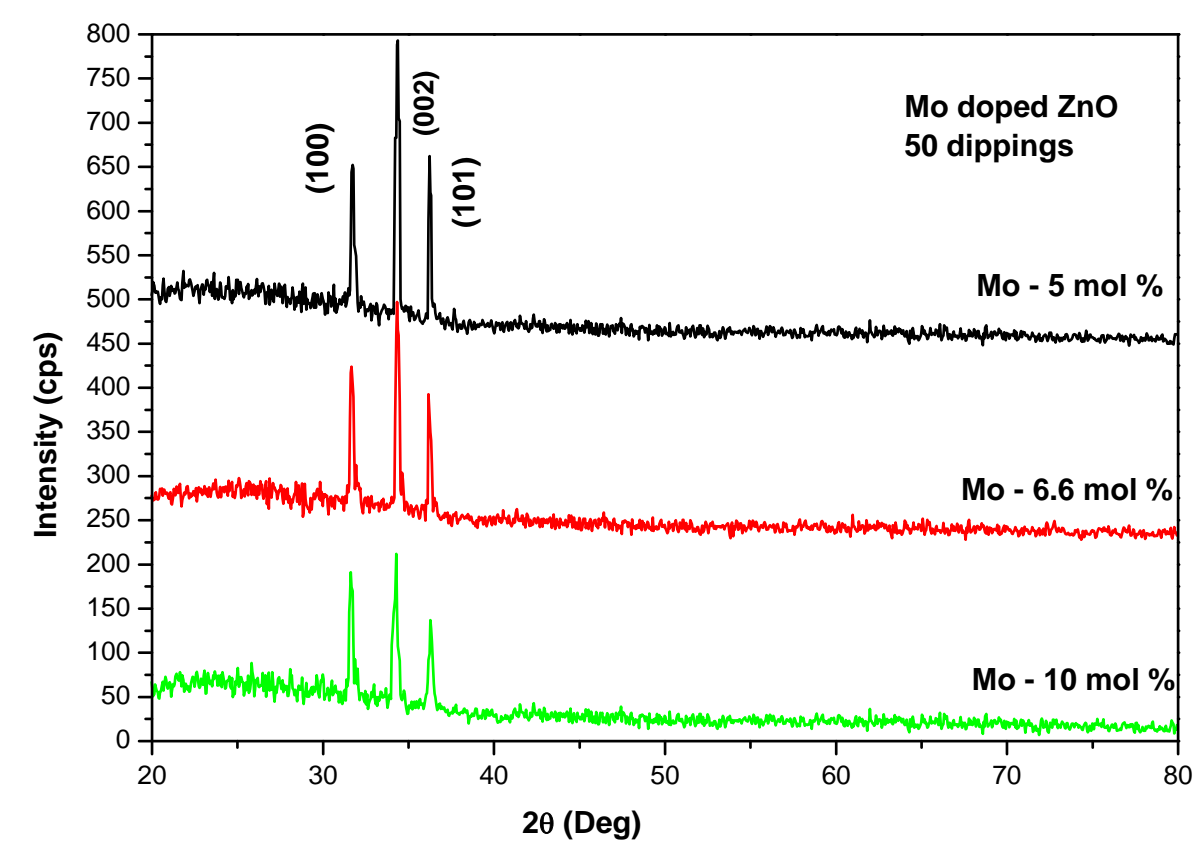

Fig.1-XRD patterns of Mo doped $\mathrm{ZnO}$ thin films
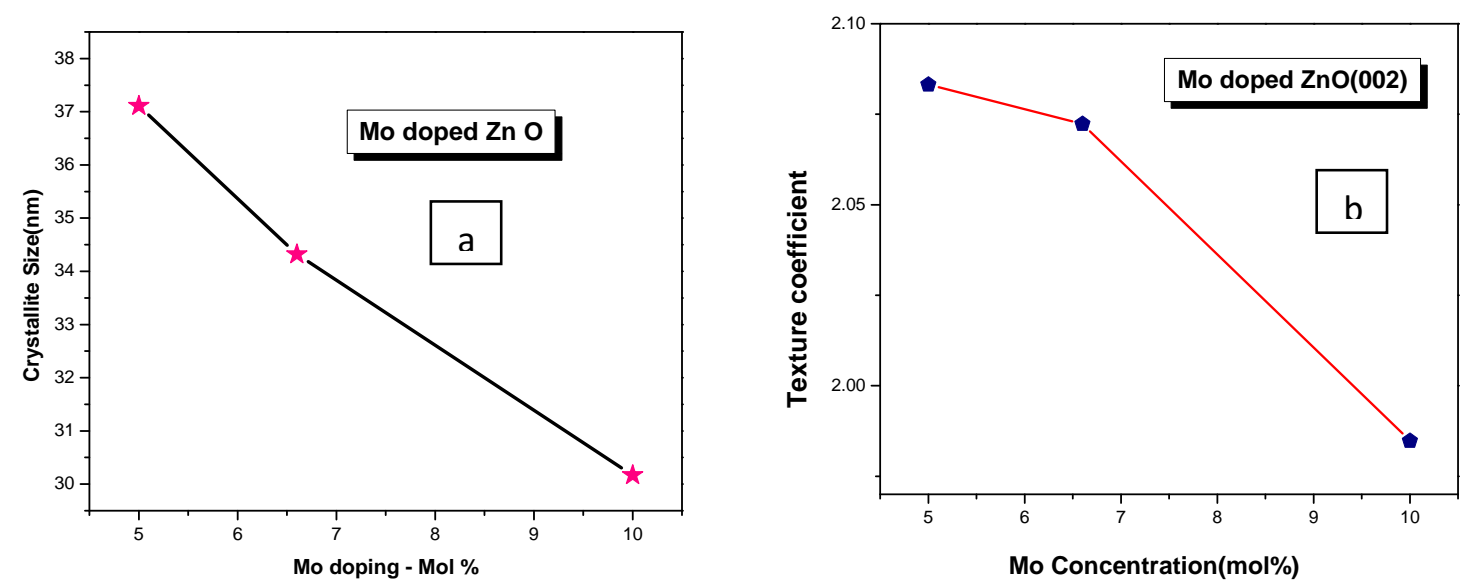

Fig.2 (a) and (b) - Variation of Crystallite size (a) and Texture coefficient (b) with Mo mol \%. 

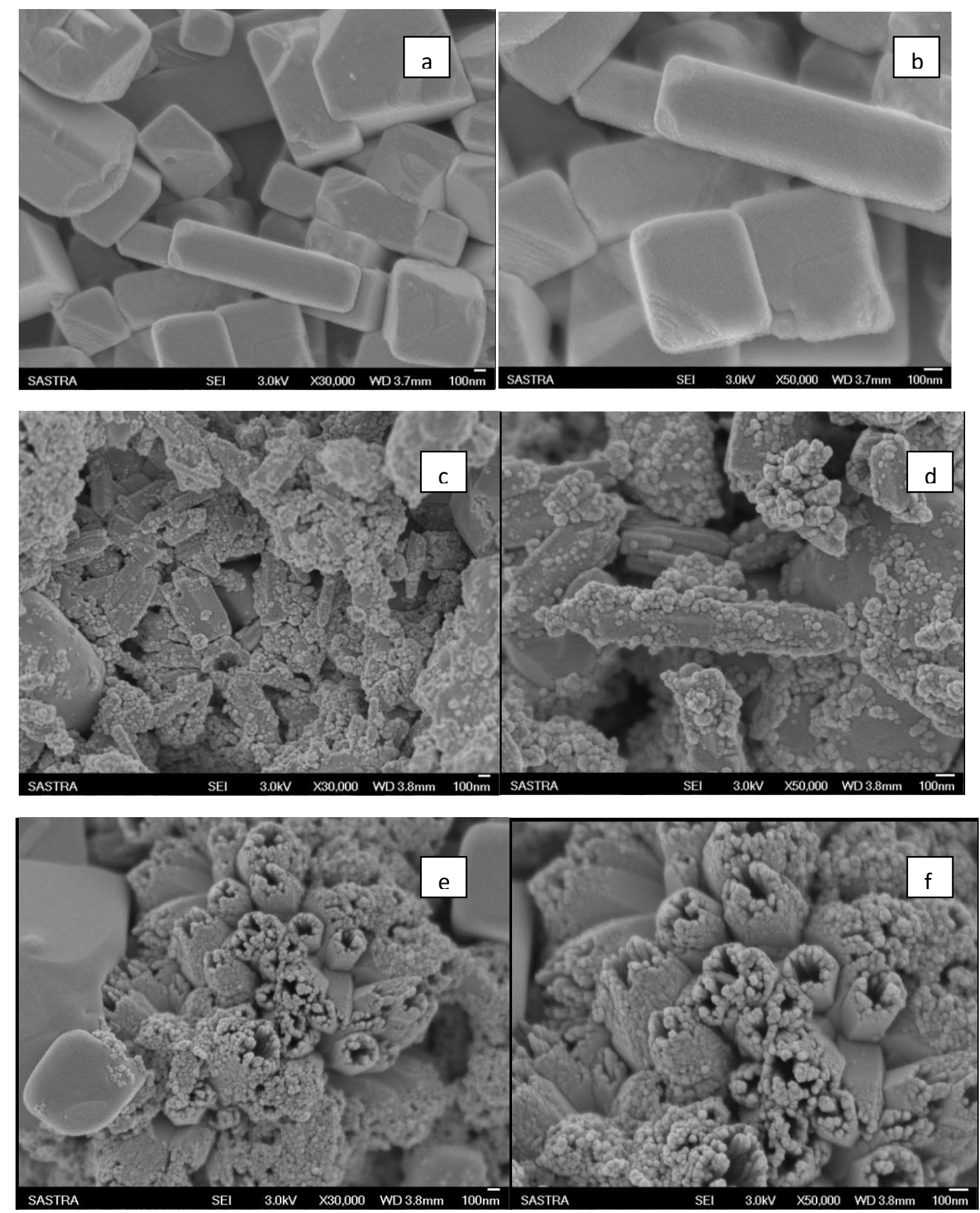

Fig.3. Surface morphology of Mo-doped $\mathrm{ZnO}$ thin films with two different magnifications (a, b) for $5 \mathrm{~mol} \%(c, d)$ for $6.6 \mathrm{~mol} \%$ and $(e, f)$ for $10 \mathrm{~mol} \%$ of Mo. 

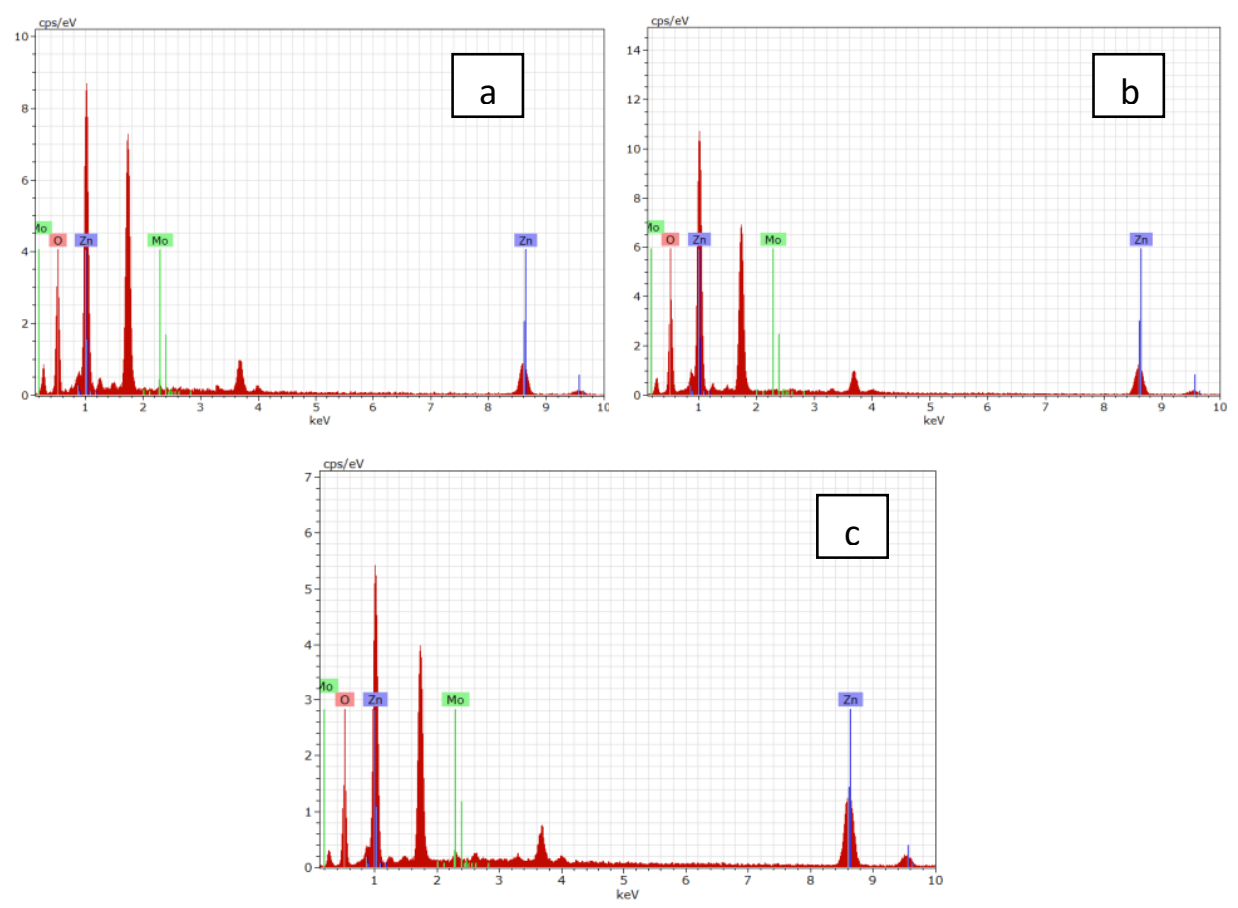

Fig.4 (a),(b) and(c) - EDAX analysis of Mo doped ZnO thin films with Mo doping \% of $5,6.6$ and 10

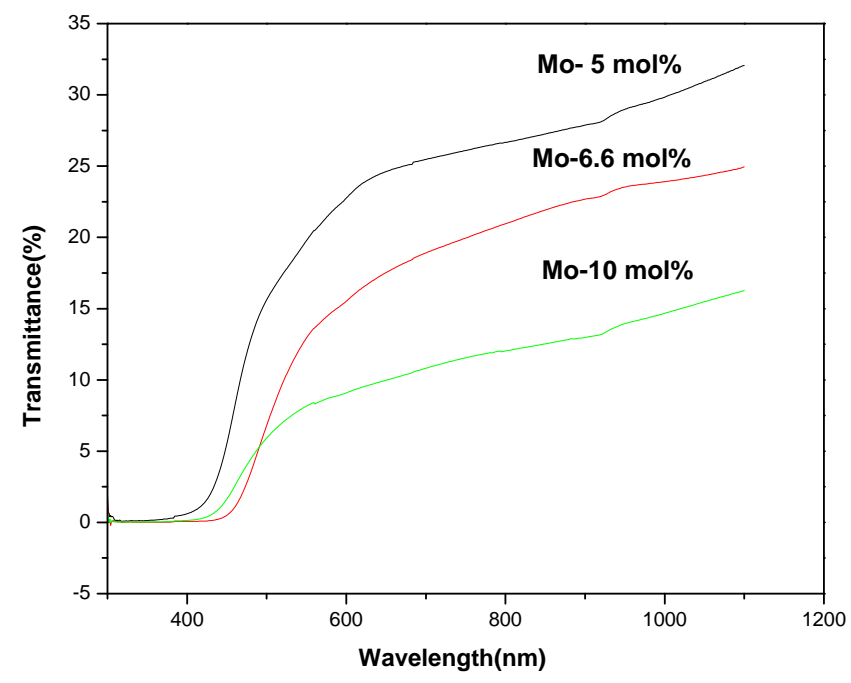

Fig.5 (a) - Transmittance graph of Mo doped $\mathrm{ZnO}$ films. 


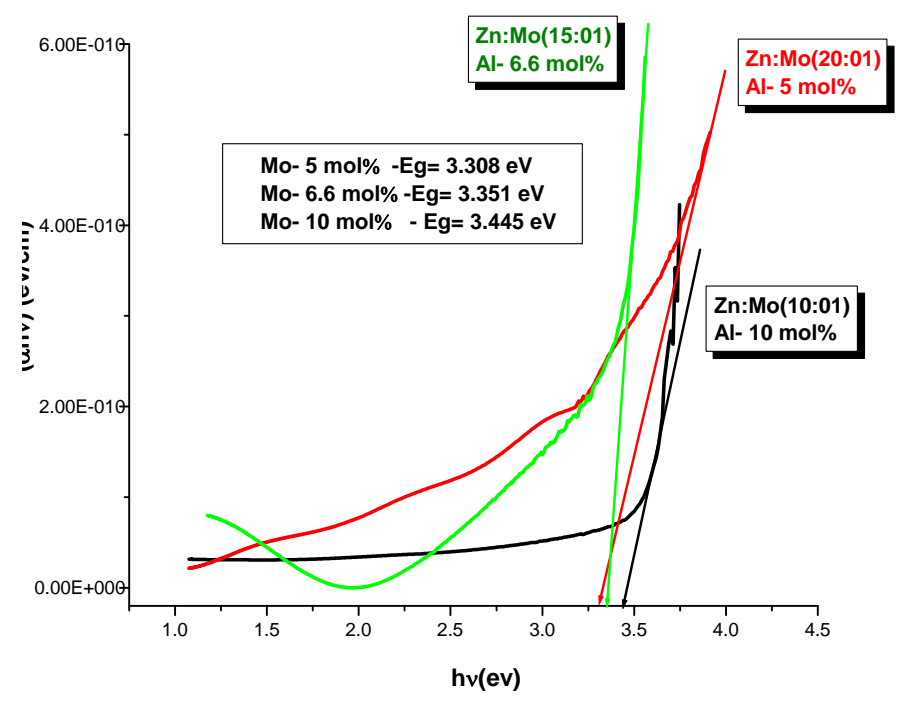

Fig. 5 (b) - Band gap of Mo doped ZnO thin films.
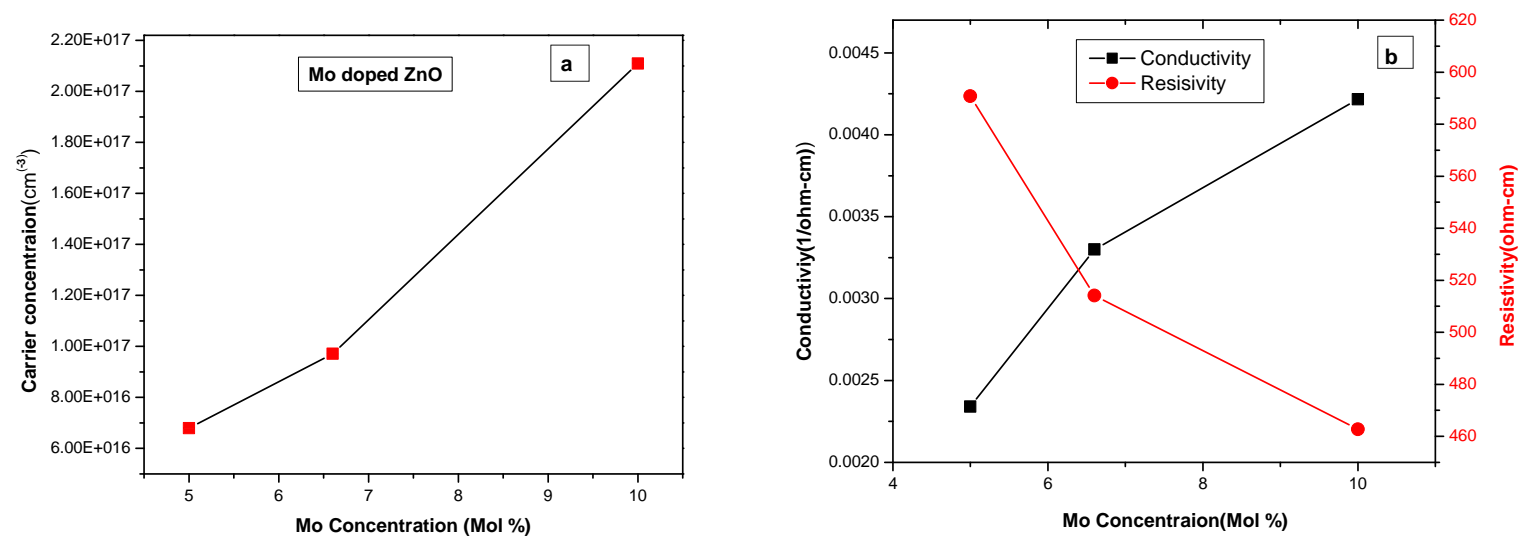

Fig.6. (a) \& (b) - shows variation of carrier concentration, conductivity \& resistivity with Mo mol\% respectively. 


\begin{tabular}{|c|c|c|c|c|c|c|}
\hline Film & $a(\AA)$ & $c(\AA)$ & Volume $\left(\AA^{3}\right)$ & c/a ratio & $\begin{array}{c}\text { Crystallite } \\
\text { Size-D } \\
(\mathrm{nm})\end{array}$ & $\begin{array}{c}\text { Micro } \\
\text { Strain- } € \\
\mathrm{x} 10-3\end{array}$ \\
\hline $\begin{array}{c}\text { Standard ZnO } \\
(\# 36-1451)\end{array}$ & 3.249 & 5.206 & 47.62 & 1.6023 & & \\
\hline $5 \mathrm{~mol} \%$ of Mo & $3.2451(4)$ & $5.2049(9)$ & $47.511(9)$ & 1.6039 & 37.11 & 3.09 \\
\hline $6.6 \mathrm{~mol} \%$ of Mo & $3.2434(5)$ & $5.2017(8)$ & $47.508(1)$ & 1.6037 & 34.32 & 3.49 \\
\hline $10 \mathrm{~mol} \%$ of Mo & $3.2419(5)$ & $5.1990(6)$ & $47.502(9)$ & 1.6036 & 30.17 & 3.71 \\
\hline
\end{tabular}

Table.01-Lattice constants, Crystallite Size and Strain of Mo doped ZnO

\begin{tabular}{|c|c|c|c|}
\hline Film & $\begin{array}{c}\text { Resistivity } \\
(\mathbf{o h m - c m})\end{array}$ & $\begin{array}{c}\text { Conductivity } \\
(\mathbf{1} / \mathbf{o h m}-\mathbf{c m})\end{array}$ & $\begin{array}{c}\text { Carrier concentration } \\
\left(\mathbf{c m}^{-3}\right)\end{array}$ \\
\hline $10 \mathrm{~mol} \%$ of Mo & $4.627 \times 10^{2}$ & $4.221 \times 10^{-03}$ & $2.109 \times 10^{17}$ \\
\hline $6.6 \mathrm{~mol} \%$ of Mo & $5.141 \times 10^{2}$ & $3.301 \times 10^{-03}$ & $9.711 \times 10^{16}$ \\
\hline $5 \mathrm{~mol} \%$ of Mo & $5.908 \times 10^{2}$ & $2.346 \times 10^{-03}$ & $6.797 \times 10^{16}$ \\
\hline
\end{tabular}

Table.02- Resistivity, Conductivity and carrier concentration of Mo doped $\mathrm{ZnO}$ 